\title{
Management of Ovarian Cystic Tumor: Diagnosis, Management, and Its Follow-Up-Case Presentation of Three Patients and Literature Review
}

\author{
Babacar Biaye, Jacque Raiga, Moussa Diallo, Reda Jafer, Abdoul Aziz Diouf, Bernard Benoit, \\ Bruno Carbone
}

Gynecological and Obstetric Clinic of Aristide Hospital Le Dantec of Dakar, Dakar, Senegal

Email: drbabacarbiaye@yahoo.fr

How to cite this paper: Biaye, B., Raiga, J., Diallo, M., Jafer, R., Diouf, A.A., Benoit, B. and Carbone, B. (2020) Management of Ovarian Cystic Tumor: Diagnosis, Management, and Its Follow-Up-Case Presentation of Three Patients and Literature Review. Open Journal of Obstetrics and $G y$ necology, 10, 25-40.

https://doi.org/10.4236/ojog.2020.101003

Received: October 7, 2019

Accepted: December 28, 2019

Published: December 31, 2019

Copyright (c) 2020 by author(s) and Scientific Research Publishing Inc. This work is licensed under the Creative Commons Attribution International License (CC BY 4.0).

http://creativecommons.org/licenses/by/4.0/

\begin{abstract}
The diagnosis and management of ovarian cystic tumor is sometimes difficult. In this manuscript, we wish to summarize this issue by showing three cases. Ultrasound and Color Doppler are very useful to diagnose the presence of this tumor but also to distinguish between benign and malignant. Pelvic MRI is also a strong tool and is sometimes mandatory. HE4 and CA125 are often useful as a serum diagnostic marker of malignancy, but not always so. Recently, laparoscopic management has gained popularity; however, great caution should be exercised during laparoscopic operative procedures, as this may lead to intraperitoneal malignant cell spreading/proliferation when the tumor is malignant. During the surgery of malignant tumor, irrespective of laparoscopic or laparotomic, intraperitoneal rupture should be avoided. Since the final diagnosis must be made by histological examination, the patient must always be informed of this possibility.
\end{abstract}

\section{Keywords}

Ovarian Cyst Tumor, Diagnosis, Management, Prognosis

\section{Introduction}

Ovarian cysts sometimes cause diagnostic and therapeutic dilemma: some of them are difficult to identify. Some cysts are overdiagnozed, whereas others are underdiagnosed. Thus, clinicians must be cautious to avoid operating functional cysts and also not to overlook malignant tumors [1]. A vaginal ultrasound and Color Doppler have now been widely employed for the diagnosis. Computed 
tomography and magnetic resonance imaging also provide useful information. Serum markers are also important. Histological examination, both during and after surgery, is mandatory for the appropriate treatment. However, intra-surgical histologic examination does not always provide the diagnosis consistent with the final histological diagnosis: this is true especially to borderline tumors (low potential malignancy) and mucinous tumors [2]. We here, describing three cases, highlight this issue based on the literature review and our experiences.

\section{Observations}

\subsection{First Case}

This is a 53-year-old menopausal patient with two children with no specific history. She consulted for abdominal volume increase with intestinal transit disorder with constipation type. The ultrasound found a normal-sized uterus with an endometrium that looked like a second part of the cycle. She also found large tumor ovaries $77 \times 58 \mathrm{~mm}$ on the left and $90 \times 52 \mathrm{~mm}$ containing small cysts with vascularized internal vegetations and a fluid collection in the Douglas (Figure 1).

MRI showed a bilateral ovarian mass with internal vegetations without fat tissue objectified in the mass. The PET scan did not visualize any pelvic and extra-pelvic extension of the tumor.

The level of CA 125 is high: $355 \mathrm{U} / \mathrm{ml}$.

The patient was treated with median laparotomy. The exploration found two annual masses with dense pelvic adhesions.

A peritoneal fluid sample is taken and then a bilateral adnexectomy. The extemporaneous examination found a bilateral borderline serous tumor. Complementary procedures were performed including a total hysterectomy with bilateral adnexectomy, an omentectomy, an appendectomy and multiple peritoneal biopsies.

The definitive histology of the operative specimen showed:

- Hysterectomy specimen with bilateral adnexectomy: 11- and 8.6-cm bilateral ovarian tumor with micropapillary borderline serous tumor type (Figure 2); Epiploon: non-invasive epithelial implants;

- Douglas-fir biopsies entitled "peritoneum": absence of peritoneal implants;

- Chronic obliterating appendicitis.

No additional postoperative procedure was performed. It enjoys surveillance every six months without any particularity found.

\subsection{Second Case}

This is a 44-year-old first pregnancy who consults for chronic abdominopelvic pain.

Ultrasound shows a normal size uterus. The right ovary presents two cysts: an anechoic good of $20 \times 10 \mathrm{~mm}$;

one of $24 \times 20 \mathrm{~mm}$ with irregular internal vegetation of $12 \times 10 \mathrm{~mm}$ without detectable vascularization (Figure 3 ). 


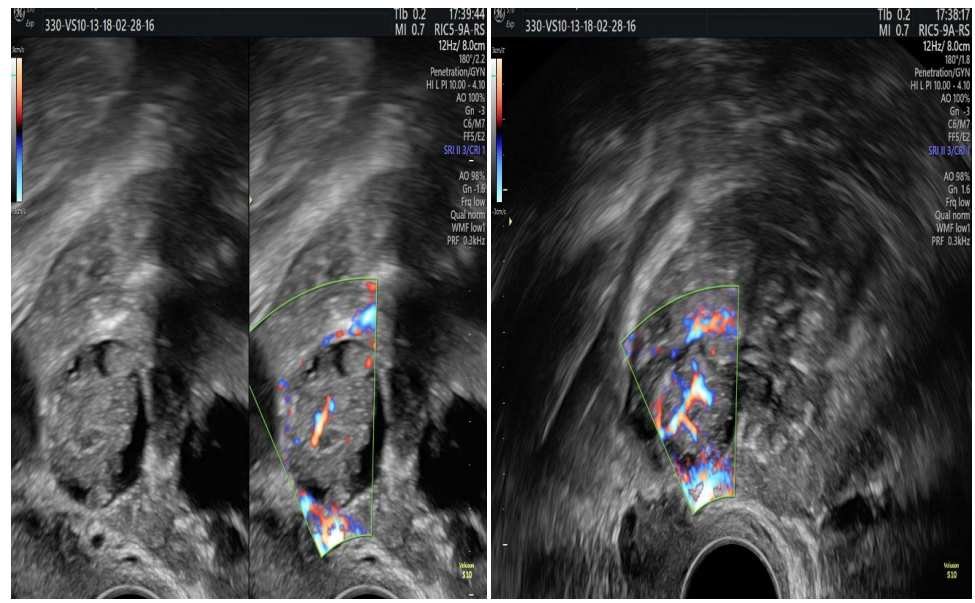

Figure 1. Bilateral ovarian cyst with hyper vascular internal vegetations.
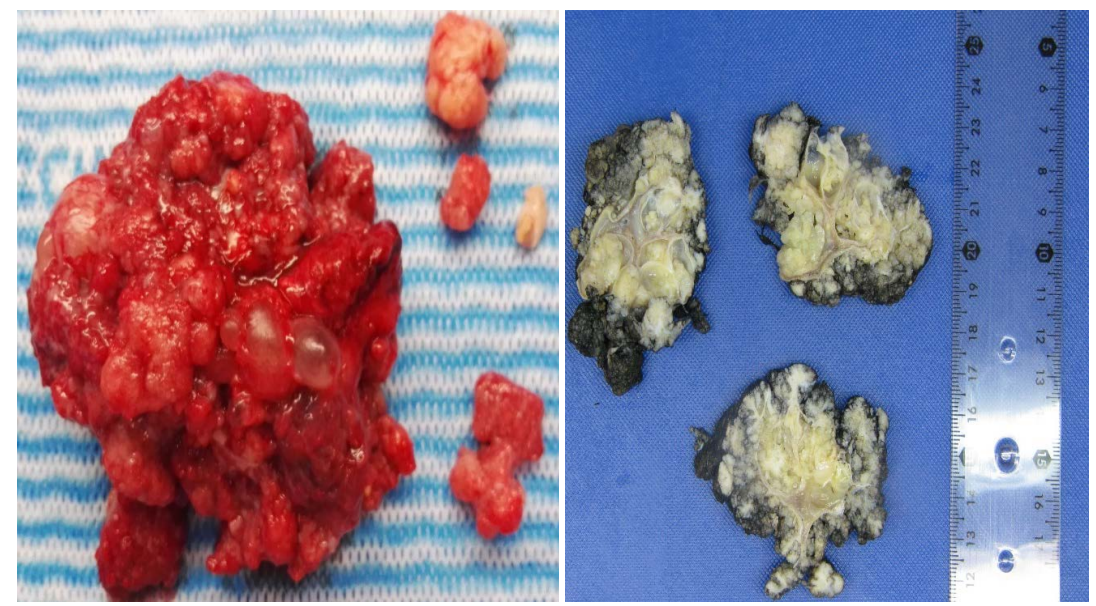

Figure 2. Macroscopic appearance of the ovaries.

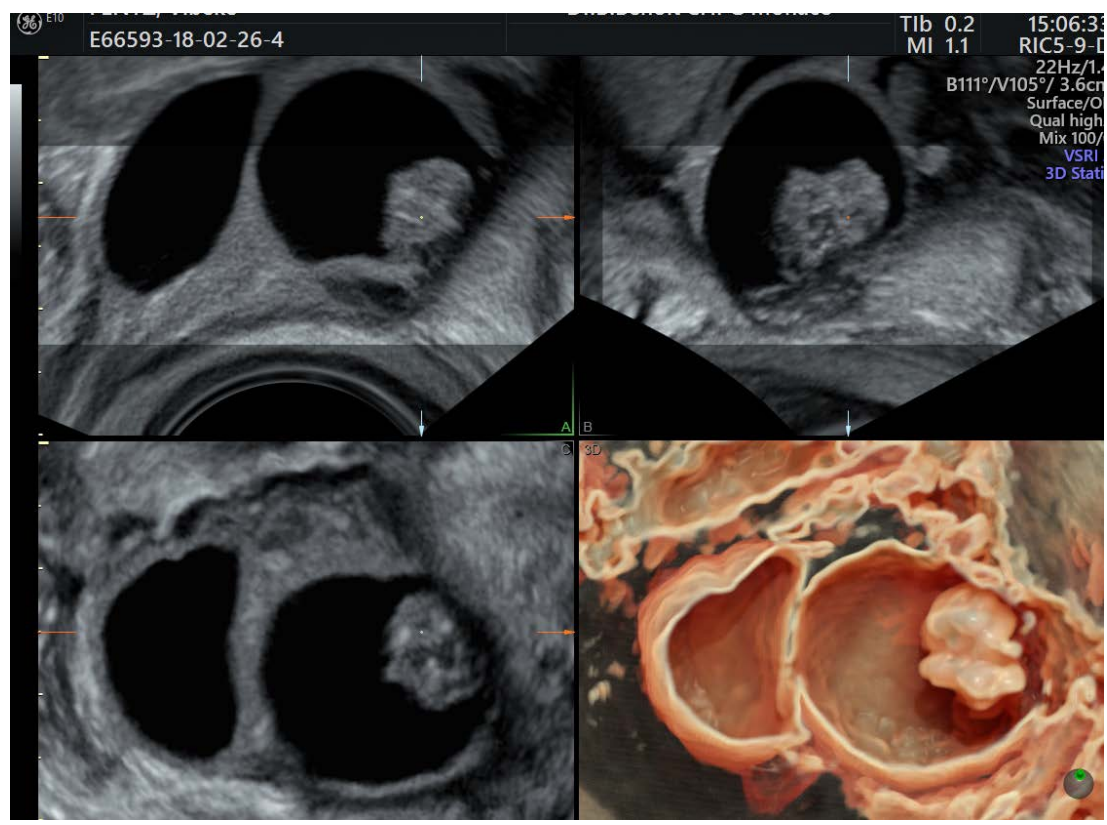

Figure 3. Right ovarian cyst with vegetation in $2 \mathrm{D}$ and $3 \mathrm{D}$ mode. 
The CA125 level is increased to $193 \mathrm{U} / \mathrm{ml}$.

Laparoscopy is performed and the inspection has a right ovarian cyst of benign appearance with no suspicious external vegetation. A straight adnexectomy is performed with extraction in a laparoscopic bag whose extemporaneous examination has revealed a benign cyst. No additional gesture was associated.

The definitive histology was in favor of a papillary serous cystadenofibroma with focal atypia.

\subsection{Third Case}

This is a 19-year-old patient with no history of chronic pelvic pain.

Ultrasound showed a normal size uterus. The left ovary carries a $40 \times 24 \mathrm{~mm}$ cyst prolapsed in Douglas-fir with several irregular vascularized septa (Figure 4). The right ovary was normal.

Pelvic MRI found the same images of vascularized cloisonné cysts of the left ovary.

Tumor marker assay revealed a moderate increase in CA125 at $53 \mathrm{U} / \mathrm{ml}$.

Careful laparoscopic exploration showed a left cystic ovary without extra-ovarian veins. Peritoneal cytology was performed and closed cystectomy was performed without cystic rupture with laparoscopic bag extraction. The extemporaneous examination found a benign mucinous tumor. No additional gesture was associated.

The definitive histology returned with endocervical mucinous cystadenoma of the left ovary.

\section{Discussion}

\subsection{Epidemiology}

It is difficult to get an exact idea of the incidence of ovarian cysts in the general population. The data available in the literature mainly come from cysts that have

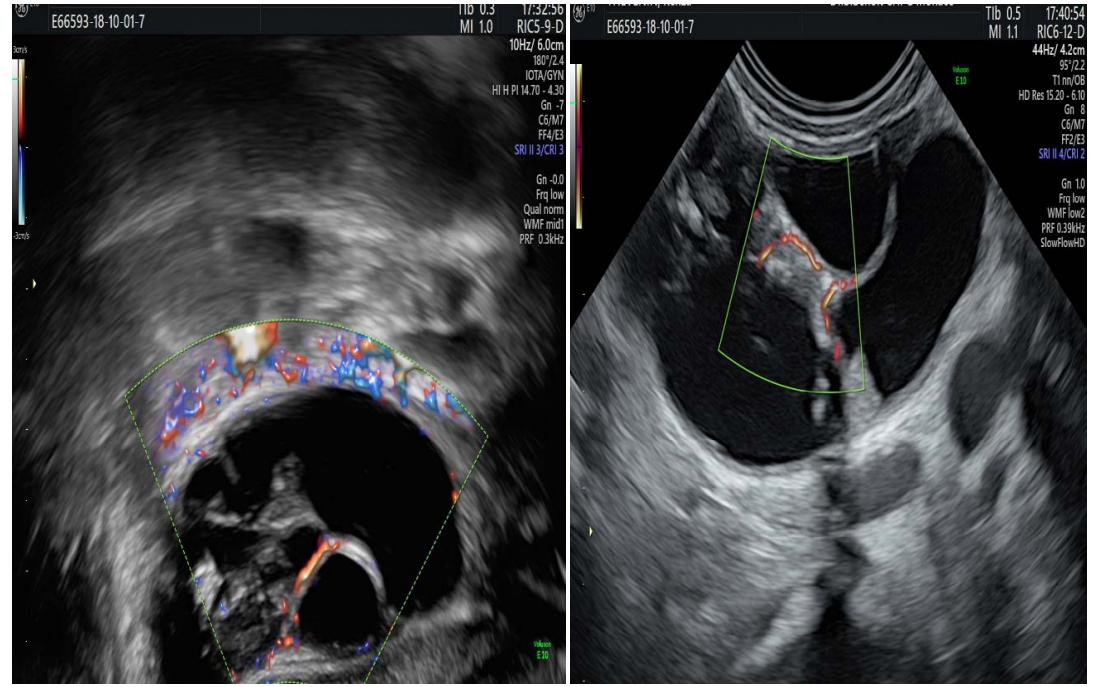

Figure 4. Left ovarian cyst with several vascularized septa. 
been operated on and/or data from the pathology anatomy charts. In France, the use of the information system medicalization program (PMSI) makes it possible to have an approximate incidence of ovarian cysts.

\subsubsection{Incidence in the General Population}

A German study estimated the incidence in general population of benign ovarian cysts diagnosed. It was a prospective cohort of 396,000 women, all aged 18 to 65 , asymptomatic. It had an incidence of $16.7 \%$. The median age of diagnosis was 28.5 years [3] [4].

\subsubsection{Incidence in Postmenopausal Women}

The prevalence of simple ovarian cysts, demonstrated by ultrasonography, in asymptomatic menopausal women has been estimated to be between $14 \%$ and $18 \%$ according to several studies [4] [5]. Modesitt et al. systematically performed ultrasounds in a population of 15,106 asymptomatic women over 50 years of age for ovarian cancer (NP2) screening [6]. Of these patients, 2763 (18\%) patients had 3259 unilocular cysts, which were followed for an average of 6.3 years [ 4 days - 14 years]. The prevalence of cysts was greater before age $55(25.1 \%)$ than at age $55(14.7 \%, \mathrm{p}<0.001)$.

\subsubsection{Incidence in Women of Childbearing Age}

Several studies have estimated the proportion of benign ovarian tumors on endovaginal ultrasound at about $6.6 \%-7 \%$ in asymptomatic women during periods of genital activity [7] [8] (NP2). In these two studies, ovarian cysts were defined by diameters greater than $25 \mathrm{~mm}$ in a series of 335 women [9] and 30 $\mathrm{mm}$ in a series of 428 women, respectively [10]. For the majority of them, these benign cysts disappeared spontaneously: disappearance of $82 \%$ at 3 months [7], and $65 \%$, of those who had persisted after the first menstruation, at 3 months [10]. No statistically significant association was found in these statistically significant association studies between the presence of cysts and BMI, age, parity [8] [10] or smoking [8].

\subsection{Diagnostic Approach}

\subsubsection{Clinical}

Ovarian cysts are most often asymptomatic or responsible for moderate and unspecific signs: metrorrhagia, pelvic pain, irregularity of menstrual cycles or simple gene, with gravity type. In most published retrospective series, abdominal pain is the most common inaugural sign at any age [9]. It was the common sign in our three patients.

In most series, abdominal and pelvic pain is acute in more than half of cases [9] [11] [12] [13]. It sometimes associates nonspecific signs with constipation, nausea, loss of appetite, fever explained by the tonicity of pulsatility of gonadotropins at this time of life. Their management is identified with that of the adult [14] [15].

In about $20 \%$ of the main series, abdominal distension may be caused by a 
painless mass found on the abdominal palpation associated with some signs of compression, dysuria or recent constipation, especially in postmenopausal women [9] [11] [12] [13]. This table corresponded exactly to that of our first clinical case.

Ovarian cysts are sometimes discovered in the course of an infertility assessment, the discovery of an endometrioma should cause suspicion of pelvic endometriosis more extensive and requires laparoscopy.

\subsubsection{Morphological Examinations * Ultrasound}

Because of its simplicity and cost, ultrasound remains the first-line examination. The recommendations of the French National College of Gynecologists and Obstetricians (CNGOF) 2001 validated the endovaginal use of ultrasound for the diagnosis of ovarian masses.

Ultrasound meets essential quality criteria which must allow by the description a conclusion of the sonographer on the right or left and intra-ovarian location or not; it must allow the simple classification of the adnexal mass and allow one or more etiological diagnoses to be considered (grade A).

The nomenclature of the IOTA group has been validated by the International Society of Ultrasound in Gynecology and Obstetrics (ISUOG).

The use of the ultrasound terminology of ovarian tumors defined by the IOTA group (grade A) is recommended. Classification of the same group can also be used [14] [15] [16].

\section{* Doppler}

In descriptive ultrasound semeiology, Doppler adds two types of arguments: qualitative vascular mapping; and a quantitative hemodynamic evaluation of the circulating fluxes. Mercé et al. [17] confirmed that $90 \%$ of malignant tumors had central vascularity and that $98 \%$ of benign tumors had peripheral vascularity. They also found that $100 \%$ of cancers had a color Doppler noticeable flow with a high frequency endovaginal tube. A color signal was also observed on $83 \%$ of functional cysts and $52 \%$ of organic cysts. It is necessary to know to look for Doppler signals in the wall of the cyst, in the partitions and in the vegetations as well as in the solid zones. Kinkel et al. validated doppler use in a meta-analysis demonstrating its contribution to benign/malignant [18] NP1 discrimination.

A vascularization index can be measured: the power doppler index or PDI. Marret et al. [19] [20] showed that it was discriminating to differentiate benign and malignant but that the characterization of the vascular image of the tumor with Doppler energy by an expert was superior. The location and distribution of the vessels within the tumor is important [21]. Guerriero et al. [22] demonstrated that the qualitative use of Doppler was more effective for the diagnosis of malignancy than 2D ultrasound alone, due to better specificity (94\% versus $89 \%, \mathrm{p}$ $=0.001$ ), with sensitivity similar ( $95 \%$ versus $98 \%, \mathrm{p}=0.44$ ). Doppler is often now integrated into the models as we will see.

\section{* Magnetic Resonance Imaging and Computed Tomography}


$\mathrm{MRI}$ and $\mathrm{CT}$ are the second-line tests requested after endovaginal ultrasound for the characterization of so-called complex or indeterminate masses. For better diagnosis, the first and third clinical cases benefited from an MRI and a pelvic $\mathrm{CT}$ that returned to favor a strong suspicion of malignancy of these cysts.

MRI provides better tissue characterization than Doppler ultrasound or CT. Pelvic MRI during the discovery of an indeterminate mass in ultrasound is therefore recommended [23] [24] [25]. The protocol for performing a pelvic MRI to characterize an indeterminate or complex adnexal mass must include morphological sequences $\mathrm{T} 1$ and $\mathrm{T} 2$. In the case of a tissue portion, perfusion and diffusion imaging is recommended. If there is any doubt as to whether a pelvic cystic lesion is ovarian or not, pelvic MRI should be preferred over CT. MRI is not a first-line technique for the differential diagnosis between functional and organic ovarian lesion. It may be useful in case of doubt in clinical diagnosis between polycystic ovary syndrome or ovarian hyperstimulation syndrome and multilocular ovarian tumor [26]. A risk-benefit balance should be evaluated on a case-by-case basis by the clinician and the radiologist and information should be given to the patient. In an emergency setting in pregnant women, pelvic MRI is an alternative to CT for exploration of acute pelvic pain in case of doubt clinical or ultrasound diagnosis [27] [28] [29] [30].

\section{Biology Report}

The most studied ovarian tumor markers are Cancer Antigen 125 (CA125) and Human Epididymis Protein 4 (HE4) [31] [32] [33]. Their performance is superior to that of CA19-9, CA72-4 and carcinoembryonic antigen which are no longer recommended for the diagnosis of suspected benign ovarian tumors [34] [35] [36] [37]. All of our three cases have just benefited from CA125 as an assay for tumor markers.

\subsection{Surgical Management}

The management of these suspect cysts must obey these questions:

Which surgical approach?

What operative gesture?

What mode of supervision?

\subsubsection{Which Surgical Approach: Laparoscopy or Laparotomy?}

In all cases, the surgical treatment must favor the laparoscopic approach. It has many advantages over laparotomy: decreased parietal complications, infectious risk, aesthetic damage, adhesion risk, postoperative pain and hospital stay [1] [38] [39]. Laparoscopic treatment should be considered when benign criteria are present: fluid or dermoid content, less than 3 thin septa, thin wall $(<3 \mathrm{~mm})$, absence of vegetation, normal doppler, CA125 $<35 \mathrm{U} / \mathrm{ml}$. The critical size beyond which laparoscopy is difficult to perform under good safety conditions is discussed, more commonly accepted, but several teams have shown the possibility of treating large cysts by laparoscopy subject to compliance with the rules of caution [39] [40] [41]. Our last two cases benefited from laparoscopy because of 
the tumor size but also criteria of tumor discrimination.

However, it is important to recognize that this approach is not without oncological risks. They are linked on the one hand to the risk of cancer gone unnoticed, and therefore inadequate management, and to the risk of spread either by default of treatment or by diffusion related to pneumoperitoneum. Blanc et al., In a multicenter, evidence-level study 3 , showed that inadequate management of cancer not diagnosed by laparoscopy could be an early-stage disseminator or underestimate the initial assessment. Of 78 cases of malignant ovarian cysts, $17 \%$ or $22 \%$ appeared benign preoperatively and intraoperatively [41]. In addition, numerous clinical cases of trocar port tumor graft have been described after laparoscopic laparoscopy [42] and cases of peritoneal dissemination [1] [39] [43]. The recent review of Canis et al. [44] takes stock of animal experimental studies on the risk of dissemination in surgery. Thus, 6 studies found no significant difference in the frequency of parietal metastases between the abdominal and laparoscopic pathways [45] [46] [47]. In contrast, four other studies found a significantly higher risk of parietal metastases in the laparotomy group [48] [49] [50] [51]. Concerning the mechanism of tumor grafts on a trocar orifice, the haematogenous pathway seems unlikely [52]. A mechanism for the aerosolization of tumor cells that may exist during leakage around the trocar or during rapid exsufflation after removal of the trocar [40] [41] is described. Direct contamination seems to be the essential mechanism. The possibility of contamination of trocar orifices is directly related to the cell volume of the intra-abdominal tumor [52] [53] [54] [55]. This direct contamination may occur during extraction in the absence of a protective bag [52]. The trocars most frequently contaminated are the trocars used by the operator compared to those of the assistant. Tumor grafts on trocar orifices are also favored by removal of contaminated trocars and loss of pneumoperitoneum [52] [53] [54] [55].

Laparotomy may be necessary because of a very high suspicion of cancer with extra-ovarian dissemination or intraoperative findings. It is then a median laparotomy that must be performed. It may also be necessary in case of contraindication to laparoscopy or difficulties during surgery for a cyst of benign appearance; then a limited size (NP5) transverse laparotomy [39] will be preferred.

This laparotomy can be proposed from the outset if there is a contraindication to laparoscopy or a cyst volume too high $\geq 10 \mathrm{~cm}$. This laparotomy can also be decided if there is a very strong presumption of ovarian cancer during the initial assessment or if the management of a suspected ovarian cyst does not seem to be feasible under conditions of sufficient safety [39].

\section{* Place of the extemporaneous examination??}

The extemporaneous examination is irrelevant in the case of a thin-walled cyst, unless the blood level of inhibin is high, in order to exclude a tumor from the cystic granulosa. In the presence of exokystic or endocystic vegetations, extemporaneous examination is permitted for the diagnosis of borderline tumor, if the pathologist considers himself to be involved in this diagnosis. This examination was performed in our three patients and allowed to adopt a more logical 
therapeutic attitude.

In the presence of solid areas in a benign serous or mucinous tumor, extemporaneous examination is permissible to verify the absence of another associated tumor, or of a carcinoma focus. In case of association with a known cancer in the patient, the extemporaneous examination is lawful on any unusual zone, provided that the pathologist is informed of the context. Three meta-analyzes of the relevance of extemporaneous examination in ovarian tumors are found in the literature [56] [57]. Many local experiments are also reported [58] [59]. The literature shows good sensitivity and specificity for the diagnosis of benign lesions and cancers in extemporaneous. The extemporaneous diagnosis of borderline tumors is less effective [16] [17] [18] [19] [22] [23] [24] [27] [28] [29] [30] [32], with an average sensitivity of 55\% (NP3), although some series report a high sensitivity, sometimes even greater than $84 \%$ [60] [61]. The greatest difficulties and therefore the poorest results are reported for mucinous lesions and large lesions (NP4) [62] [63]. Some publications emphasize the different performances of pathologists specialized or not in gynecopathology in these situations (NP4) [64] [65] [66].

What operative gesture?

Whichever pathway is the first step, it is important to proceed with a rigorous inspection in order not to ignore a malignant lesion: careful inspection of the ovaries, tubes and the entire peritoneum in search of possible suspicious growths. Peritoneal cytology is performed systematically [1] [39].

\subsubsection{Conservative or Radical Treatment??}

In young women wanting pregnancy, the extemporaneous examination finds all its interest in this context. Laparoscopy will be performed by performing a closed cystectomy with extraction in a sealed bag to avoid the risk of parietal contamination. It is logical to avoid ovarian fragmentation as much as possible, so as to avoid the risk of dissemination and to facilitate pathological examination [1] [39]. This therapeutic attitude was adopted in the second and third patients who underwent unilateral adnexectomy and cystectomy with laparoscopic bag extraction.

If the result of the extemporaneous examination is in favor of at least one borderline tumor, a laparo-conversion will be made and bilateral adnexectomy, omentectomy and multiple peritoneal biopsies will be performed. In the absence of a desire for pregnancy, the recommendations will be to perform a hysterectomy with bilateral adnexectomy, an omentectomy, a peritoneal biopsy and an appendectomy [67].

In postmenopausal women, although ovarian function after menopause remains controversial [68] [69], it seems nevertheless limited. There are no formal arguments for recommending systematic bilateral adnexectomy after menopause even though it is practiced by many authors. It seems legitimate to reduce the risk of ovarian cancer (NP2).

In the Nurse Health Study, the relative risk of ovarian cancer in patients who 
underwent bilateral oophorectomy was 0.03 for women $<45$ years with $95 \%$ CI [0.01 - 0.14], for women aged 45 to 54 years of $0.0495 \%$ CI [0.01 - 0.16] and for patients over 55 years of $0.0795 \%$ CI [0.01 - 0.60] (NP2) [60]. Co-surgical management may be recommended in the menopause unless the cyst has the morphological, vascular and/or biological characteristics of the malignancy (NP5). Hysterectomy, classically associated with laparotomy, is theoretically excluded by the laparoscopic management of ovarian cysts. As a result, some authors emphasize the need for the associated exploration of the endometrium by hysteroscopy and uterine lining abrasion [1] [39] [70].

In all cases, during the coeliosurgery these suspicious cysts, an extemporaneous examination is recommended and will determine the continuation of the operative act.

In our first case, in addition to menopause, the elements of morphological examinations (ultrasound, CT, MRI) and tumor markers were very much in favor of a malignant cyst. What motivated laparotomy immediately. The extemporaneous examination was in favor of a borderline tumor which allowed to make complementary gestures.

If the cyst proves to be malignant at the extemporaneous, a laparo-conversion is recommended and the realization of a total hysterectomy and bilateral adnexectomy associated with an omentectomy an appendectomy and the lumbar-aortic and pelvic lymphadenectomy [1] [39] [71].

\subsubsection{What Mode of Supervision}

The follow-up is based on the combination of the clinical examination, the CA 125 dosage, even if this marker is not very sensitive and not very specific, and the endovaginal ultrasound which allows in particular the surveillance of the contralateral ovary.

Follow-up should be closer when the treatment has been conservative since the risk of recurrence is increased, especially in case of cystectomy. This follow-up must be carried out without end-of-term, given the sometimes very late onset of certain borderline cysts [1] [39].

\section{Conclusion}

Ovarian cysts should benefit from rigorous investigation. Endovaginal ultrasound is the first-line imaging examination. Its association with Doppler makes it possible to characterize the vascularization of the mass. MRI and CT are second-line exams. CA125 HE4 are the most commonly used tumor markers. Laparoscopy is currently the standard surgical technique. The extemporaneous examination is of paramount importance, especially since it must determine the continuation of the operative act. Laparotomy is indicated in the presence of a strong suspicion of malignancy.

\section{Conflicts of Interest}

The authors declare no conflicts of interest regarding the publication of this paper. 


\section{References}

[1] Raiga, J., Djafer, R., Benoit, B. and Treisser, A. (2006) Prise en charge des kystes ovariens. Journal de Chirurgie, 143, 276-284.

https://doi.org/10.1016/S0021-7697(06)73692-4

[2] Lahlou, N. and Brun, J.L. (2013) Marqueurs sériques et tumoraux ovariens dans le diagnostic des tumeurs ovariennes présumées bénignes. Journal de Gynecologie Obstetrique et Biologie de la Reproduction, 42, 752-759.

https://doi.org/10.1016/j.jgyn.2013.09.030

[3] Mimoun, C., Fritel, X., Fauconnier, A., Deffieux, X., Dumont, A. and Huchon, C. (2013) Épidémiologie des tumeurs ovariennes présumées bénignes. Journal de Gynécologie Obstétrique et Biologie de la Reproduction, 42, 722-729. https://doi.org/10.1016/j.jgyn.2013.09.027

[4] Heinemann, K., Thiel, C., Mohner, S., Lewis, M.A., Raff, T., Kuhl-Habich, D., et al. (2003) Benign Gynecological Tumors: Estimated Incidence. Results of the German Cohort Study on Women's Health. The European Journal of Obstetrics \& Gynecology and Reproductive Biology, 107, 78-80. https://doi.org/10.1016/S0301-2115(02)00308-1

[5] Greenlee, R.T.R.T., Kessel, B., Williams, C.R., Riley, T.L., Ragard, L.R., Hartge, P., et al. (2010) Prevalence, Incidence, and Natural History of Simple Ovarian Cysts among Women > 55 Years Old in a Large Cancer Screening Trial. American Journal of Obstetrics \& Gynecology, 202, 373. https://doi.org/10.1016/j.ajog.2009.11.029

[6] Modesitt, S.C., Pavlik, E.J., Ueland, F.R., DePriest, P.D., Kryscio, R.J. and van Nagell Jr., J.R. (2003) Risk of Malignancy in Unilocular Ovarian Cystic Tumors Less than 10 Centimeters in Diameter. Obstetrics \& Gynecology, 102, 594-599. https://doi.org/10.1097/00006250-200309000-00030

[7] Borgfeldt, C. and Andolf, E. (1999) Transvaginal Sonographic Ovarian Findings in a Random Sample of Women 25-40 Years Old. Ultrasound in Obstetrics \& Gynecology, 13, 345-350. https://doi.org/10.1046/j.1469-0705.1999.13050345.x

[8] Christensen, J.T., Boldsen, J.L. and Westergaard, J.G. (2002) Functional Ovarian Cysts in Premenopausal and Gynecologically Healthy Women. Contraception, 66, 153-157. https://doi.org/10.1016/S0010-7824(02)00353-0

[9] Eskander, R.N., et al. (2011) A Retrospective Review of the Effect of Surgeon Specialty on the Management of 190 Benign and Malignant Pediatric and Adolescent Adnexal Masses. Journal of Pediatric and Adolescent Gynecology, 24, 282-285. https://doi.org/10.1016/j.jpag.2011.03.012

[10] Cass, D.L., et al. (2001) Surgery for Ovarian Masses in Infants, Children, and Adolescents: 102 Consecutive Patients Treated in a 15-Year Period. Journal of Pediatric Surgery, 36, 693-699. https://doi.org/10.1053/jpsu.2001.22939

[11] Al Jama, F.E., et al. (2011) Ovarian Tumors in Children and Adolescents a Clinical Study of 52 Patients in a University Hospital. Journal of Pediatric and Adolescent Gynecology, 24, 25-28. https://doi.org/10.1016/j.jpag.2010.06.005

[12] Pienkowski, C. and Kalfa, N. (2013) Tumeurs ovariennes présumées bénignes de l'enfant et l'adolescente. Journal de Gynécologie Obstétrique et Biologie de la Reproduction, 42, 833-841. https://doi.org/10.1016/j.jgyn.2013.09.037

[13] Spinelli, C., et al. (2009) Hemorrhagic Corpus Luteum Cysts: An Unusual Problem for Pediatric Surgeons. Journal of Pediatric and Adolescent Gynecology, 22, 163-167. https://doi.org/10.1016/j.jpag.2008.07.013

[14] Kirkham, Y. and Kives, S. (2012) Ovarian Cysts in Adolescents: Medical and Sur- 
gical Management. Adolescent Medicine. State of the Art Reviews, 23, 178-191.

[15] Marret, H. and Cayrol, M. (2013) Échographie et doppler dans le diagnostic des tumeurs ovariennes présumées bénignes. Journal de Gynécologie Obstétrique et Biologie de la Reproduction, 42, 730-743. https://doi.org/10.1016/j.jgyn.2013.09.028

[16] Timmerman, D., Valentin, L., Bourne, T.H., Collins, W.P., Verrelst, H., Vergote, I., et al. (2000) Terms, Definitions and Measurements to Describe the Sonographic Features of Adnexal Tumors: A Consensus Opinion from the International Ovarian Tumor Analysis (IOTA) Group. Ultrasound in Obstetrics \& Gynecology, 16, 500-505. https://doi.org/10.1046/j.1469-0705.2000.00287.x

[17] Marret, H. (2001) Doppler Ultrasonography in the Diagnosis of Ovarian Cysts: Indications, Pertinence and Diagnostic Criteria. Journal de Gynécologie Obstétrique et Biologie de la Reproduction, 30, S20-S33.

[18] Mercé, L.T.L.T., Caballero, R.A., Barco, M.J., Bau, S. and Lopez, G. (1998) B-mode utero-ovarian and intratumoral transvaginal colour doppler ultrasonography for differential diagnosis of ovarian tumours. The European Journal of Obstetrics \& Gynecology and Reproductive Biology, 76, 97-107.

https://doi.org/10.1016/S0301-2115(97)00167-X

[19] Kinkel, K., Hricak, H., Lu, Y., Tsuda, K. and Filly, R.A. (2000) US Characterization of Ovarian Masses: A Meta-Analysis. Radiology, 217, 803-811. https://doi.org/10.1148/radiology.217.3.r00dc20803

[20] Marret, H., Sauget, S., Giraudeau, B., Body, G. and Tranquart, F. (2005) Power Doppler Vascularity Index for Predicting Malignancy of Adnexal Masses. Ultrasound in Obstetrics \& Gynecology, 25, 508-513. https://doi.org/10.1002/uog.1893

[21] Marret, H., Vinatier, L., Sauget, S., Giraudeau, B., Body, G. and Tran-quart, F. (2007) Power Doppler Index for Preoperative Ovarian Tumors Discrimination. Gynécologie Obstétrique \& Fertilité, 35, 541-547. https://doi.org/10.1016/j.gyobfe.2007.04.009

[22] Maly, Z., Riss, P. and Deutinger, J. (1995) Localization of Blood Vessels and Qualitative Assessment of Blood Flow in Ovarian Tumors. Obstetrics \& Gynecology, 85, 33-36. https://doi.org/10.1016/0029-7844(94)00293-M

[23] Guerriero, S., Alcazar, J.L., Ajossa, S., Galvan, R., Laparte, C., García-Manero, M., et al. (2010) Transvaginal Color Doppler Imaging in the Detection of Ovarian Cancer in a Large Study Population. International Journal of Gynecological Cancer, 20, 781-786. https://doi.org/10.1111/IGC.0b013e3181de9481

[24] Timmerman, D., Ameye, L., Fischerova, D., Epstein, E., Melis, G.B., Guerriero, S., et al. (2010) Simple Ultrasound Rules to Distinguish between Benign and Malignant Adnexal Masses before Surgery: Prospective Validation by IOTA Group. BMJ, 341, c6839. https://doi.org/10.1136/bmj.c6839

[25] Thomassin-Naggara, I. and Bazot, M. (2013) IRM et TDM dans le diagnostic des tumeurs ovariennes présumées bénignes. Journal de Gynécologie Obstétrique et Biologie de la Reproduction, 42, 744-751. https://doi.org/10.1016/j.jgyn.2013.09.029

[26] Huchon, C., Bats, A.S., Bensaid, C., Junger, M., Nos, C., Chatellier, G., et al. (2008) Adnexal Masses Management: A Prospective Multicentric Observational Study. Gynécologie Obstétrique \& Fertilité, 36, 1084-1090. https://doi.org/10.1016/j.gyobfe.2008.08.014

[27] Chilla, B., Hauser, N., Singer, G., Trippel, M., Froehlich, J.M. and Kubik-Huch, R.A. (2011) Indeterminate Adnexal Masses at Ultrasound: Effect of MRI Imaging Findings on Diagnostic Thinking and Therapeutic Decisions. European Radiology, 21, 1301-1310. https://doi.org/10.1007/s00330-010-2018-x 
[28] Spencer, J.A., Forstner, R., Cunha, T.M. and Kinkel, K. (2011) ESUR Guidelines for MR Imaging of the Sonographically Indeterminate Adnexal Mass: An Algorithmic Approach. European Radiology, 20, 25-35. https://doi.org/10.1007/s00330-009-1584-2

[29] Moteki, T. and Ishizaka, H. (2000) Diffusion-Weighted EPI of Cystic Ovarian Lesions: Evaluation of Cystic Contents Using Apparent Diffusion Coefficients. Journal of Magnetic Resonance Imaging, 12, 1014-1019. https://doi.org/10.1002/1522-2586(200012)12:6<1014::AID-JMRI29>3.0.CO;2-T

[30] Tremblay, E., Therasse, E., Thomassin-Naggara, I. and Trop, I. (2012) Quality Initiatives: Guidelines for Use of Medical Imaging during Pregnancy and Lactation. Radiographics, 32, 897-911. https://doi.org/10.1148/rg.323115120

[31] Lahlou, N. and Brun, J.L. (2013) Marqueurs sériques et tumoraux ovariens dans le diagnostic des tumeurs ovariennes présumées bénignes. Journal de Gynecologie Obstetrique et Biologie de la Reproduction, 42, 752-759.

https://doi.org/10.1016/j.jgyn.2013.09.030

[32] Ferraro, S., Braga, F., Lanzoni, M., Boracchi, P., Biganzoli, E.M. and Panteghini, M. (2013) Serum Human Epididymis Protein 4 vs. Carbohydrate to the Risk of Malignancy Index (RMI) or the Risk of Ovarian. Journal of Clinical Pathology, 66, 273-281. https://doi.org/10.1136/jclinpath-2012-201031

[33] Kaijser, J., VaVan Gorp, T., VaVan Hoorde, K., Van Holsbeke, C., Sayasneh, A., Vergote, I., et al. (2013) A Comparison between an Ultrasound Based Prediction Model (LR2) and the Risk of Ovarian Malignancy Algorithm (ROMA) to Assess the Risk of Malignancy in Women with an Adnexal Mass. Gynecologic Oncology, 129, 377-383. https://doi.org/10.1016/j.ygyno.2013.01.018

[34] Anton, C., Carvalho, F.M., Oliveira, E.I., Maciel, G.A.R., Baracat, E.C. and Carvalho, J.P. (2012) A Comparison of CA125, HE4, Risk Ovarian Malignancy Algorithm (ROMA), and Risk Malignancy Index (RMI) for the Classification of Ovarian Masses. Clinics, 67, 437-441. https://doi.org/10.6061/clinics/2012(05)06

[35] VaVan Gorp, T., Veldman, J., VaVan Calster, B., Cadron, I., Leunen, K., Amant, F., et al. (2012) Subjective Assessment by Ultrasound Is Superior to the Risk of Malignancy Index (RMI) or the Risk of Ovarian Malignancy Algorithm (ROMA) in Discriminating Benign from Malignant Adnexal Masses. European Journal of Cancer, 48, 1649-1656. https://doi.org/10.1016/j.ejca.2011.12.003

[36] Macuks, R., Baidekalna, I. and Donina, S. (2012) An Ovarian Cancer Malignancy Risk Index Composed of HE4, CA125, Ultrasonographic Score, and Menopausal Status: Use in Differentiation of Ovarian Cancers and Benign Lesions. Tumor Biology, 33, 1811-1817. https://doi.org/10.1007/s13277-012-0440-1

[37] Charpin, C., Bhan, A.K., Zurawski Jr., V.R. and Scully, R.E. (1982) Carcinoembryonic Antigen (CEA) and Carbohydrate Determinant 19-9 (CA 19-9) Localization in 121 Primary and Metastatic Ovarian Tumors: An Immunohistochemical Study with the Use of Monoclonal Antibodies. International Journal of Gynecological Pathology, 1, 231-245. https://doi.org/10.1097/00004347-198203000-00001

[38] Zheng, H. and Gao, Y. (2012) Serum HE4 as a Useful Biomarker in Discriminating Ovarian Cancer from Benign Pelvic Disease. International Journal of Gynecological Cancer, 22, 1000-1005. https://doi.org/10.1097/IGC.0b013e318249bee7

[39] Narducci, F., Orazi, G. and Cosson, M. (2001) Recommandations pour la pratique clinique. Kyste ovarien: Indications chirurgicale et voies d'abord. Journal de Gynécologie Obstétrique et Biologie de la Reproduction, 30, 4S59-4S67.

[40] Canis, M., Botchorishvili, R., Manhes, H., Wattiez, A., Mage, G., Pouly, J.L. and 
Bruhat, M.A. (2000) Management of Adnexal Masses: Role and Risk of Laparoscopy. Seminars in Surgical Oncology, 19, 28-35. https://doi.org/10.1002/1098-2388(200007/08)19:1<28::AID-SSU5>3.0.CO;2-C

[41] Blanc, B., Boubli, L., D’Ercole, C. and Nicoloso, E. (1994) Laparoscopic Management of Malignant Ovarian Cysts: A 78-Case National Survey. Part 1: Pre-Operative and Laparoscopic Evaluation. European Journal of Obstetrics \& Gynecology and Reproductive Medicine, 56, 177-180. https://doi.org/10.1016/0028-2243(94)90167-8

[42] Wang, P.H., Yuan, C.C., Lin, G., et al. (1999) Risk Factors Contributing to Early Occurrence of Port Site Metastases of Laparoscopic Surgery for Malignancy. Gynecologic Oncology, 72, 38-44. https://doi.org/10.1006/gyno.1998.5128

[43] Wang, P.H., Yuan, C.C., Chao, K.C., et al. (1997) Squamous Cell Carcinoma of the Cervix after Laparoscopic Surgery. A Case Report. The Journal of Reproductive Medicine, 42, 801-804.

[44] Canis, M., Botchorishvili, Wattiez, A., Pouly, J.L., Mage, G., Manhès, H. and Bruhat, M.A. (2000) Cancer and Laparoscopy, Experimental Studies: A Review. The European Journal of Obstetrics \& Gynecology and Reproductive Biology, 91, 1-9. https://doi.org/10.1016/S0301-2115(99)00251-1

[45] Hubens, G., Pauwels, M., Hubens, A., et al. (1996) The Influence of Apneumoperitoneum on Peritoneal Implantation of Free Intraperitoneal Colon Cancer Cells. Surgical Endoscopy, 10, 809-812. https://doi.org/10.1007/BF00189539

[46] Le Moine, M.C., Navarro, F., Burgel, J.S., et al. (1998) Experimental Assessment of the Risk of Tumour Recurrence after Laparoscopic Surgery. Surgery, 123, 427-431. https://doi.org/10.1016/S0039-6060(98)70164-3

[47] Bouvy, N.D., Marquet, R.L., Jeekel, J. and Bonjer, H.J. (1997) Laparoscopic Surgery Is Associated with Less Tumour Growth Stimulation than Conventional Surgery: An Experimental Study. British Journal of Surgery, 84, 358-361. https://doi.org/10.1002/bjs.1800840326

[48] Gutt, C.N., Riemer, V., Kim, Z.G., et al. (1999) Impact of Laparoscopic Colonic Resection on Tumor Growth and Spread in an Experimental Model. British Journal of Surgery, 86, 1180-1184. https://doi.org/10.1046/j.1365-2168.1999.01201.x

[49] Jones, D.B., Guo, L.W., Reinhard, M.K., Soper, N.J., Philpott, G.W., Conneth, J., et al. (1995) Impact of Pneomoperitoneum on Trocar Site Implantation of Colon Cancer in Hamster Model. Diseases of the Colon \& Rectum, 38, 1182-1188. https://doi.org/10.1007/BF02048334

[50] Whelan, R.L., Sellers, G.J., Allendorf, J.D., Laird, D., Bessler, M.D., Nowygrod, R., et al. (1996) Trocar Site Recurrence Is Unlikely to Result from Aerosolization of Tumor Cells. Diseases of the Colon \& Rectum, 39, S7-S13. https://doi.org/10.1007/BF02053799

[51] Allardyce, R., Morreau, P. and Bagshaw, P. (1996) Tumour Cell Distribution Following Laparoscopic Colectomy in a Porcine Model. Diseases of the Colon \& Rectum, 39, S47-S52. https://doi.org/10.1007/BF02053805

[52] Wu, J.S., Jones, D.B., Guo, L.W., et al. (1998) Effect of Pneumoperitoneumon Tumour Implantation with Decreasing Tumour Inoculum. Diseases of the Colon \& Rectum, 41, 141-146. https://doi.org/10.1007/BF02238239

[53] Bouvy, N.D., Marquet, R.L., Jeekel, H. and Bonjer, H.B. (1996) Impact of Gas [Less] Laparoscopy and Laparotomy on Peritoneal Tumor Growth and Abdominal Wall Metastases. Annals of Surgery, 224, 694-701. https://doi.org/10.1097/00000658-199612000-00005 
[54] Hewett, P.J., Thomas, W.M., King, G. and Eaton, M. (1996) Intraperitoneal Cell Movement during Abdominal Carbon Dioxide Insufflation and Laparoscopy. Diseases of the Colon \& Rectum, 39, S62-S66. https://doi.org/10.1007/BF02053808

[55] Thomas, W.M., Eaton, M.C. and Hewett, P.J. (1996) A Proposed Model for the Movement of Cells within the Abdominal Cavity during $\mathrm{CO}_{2}$ Insufflation and Laparoscopy. ANZ Journal of Surgery, 66, 105-106. https://doi.org/10.1111/j.1445-2197.1996.tb01123.x

[56] Sevestre, H., Ikoli, J.F. and Al Thakfi, W. (2013) Anatomie et cytologie pathologiques des tumeurs supposées bénignes de l'ovaire. Journal de Gynécologie Obstétrique et Biologie de la Reproduction, 42, 715-721. https://doi.org/10.1016/j.jgyn.2013.09.026

[57] Medeiros, L.R., Rosa, D.D., Edelweiss, M.I., Stein, A.T.A.T., Bozzetti, M.C., Zelmanowicz, A., et al. (2005) Accuracy of Frozen Section Analysis in the Diagnosis of Ovarian Tumors: A Systematic Quantitative Review. International Journal of Gynecological Cancer, 15, 192-202. https://doi.org/10.1136/ijgc-00009577-200503000-00002

[58] Heatley, M.K. (2012) A Systematic Review of Papers Examining the Use of Intraoperative Frozen Section in Predicting the Final Diagnosis of Ovarian Lesions. International Journal of Gynecological Pathology, 31, 111-115. https://doi.org/10.1097/PGP.0b013e318226043b

[59] Rose, P.G., Rubin, R.B., Nelson, B.E., Hunter, R.E. and Reale, F.R. (1994) Accuracy of Frozen Section (Intraoperative Consultation) Diagnosis of Ovarian Tumors. American Journal of Obstetrics \& Gynecology, 171, 823-826. https://doi.org/10.1016/0002-9378(94)90105-8

[60] Lax, S., Tamussino, K., Prein, K. and Lang, P. (2012) Intraoperative Frozen Sections in Diseases of the Female Genital Tract. Pathologe, 33, 430-440. https://doi.org/10.1007/s00292-012-1597-5

[61] Ilvan, S., Ramazanoglu, R., Ulker Akyildiz, E., Calay, Z., Bese, T. and Oruc, N. (2005) The Accuracy of Frozen Section (Intraoperative Consultation) in the Diagnosis of Ovarian Masses. Gynecologic Oncology, 97, 395-399. https://doi.org/10.1016/j.ygyno.2005.01.037

[62] Suprasert, P., Khunamornpong, S., Phusong, A. and Settakor, J. (2001) Malignancy in Endometriosis: Frequency and Comparison of Ovarian and Extraovarian Types. International Journal of Gynecological Pathology, 20, 133-139. https://doi.org/10.1097/00004347-200104000-00004

[63] Baker, P. and Oliva, E. (2008) A Practical Approach to Intraoperative Consultation in Gynecological Pathology. International Journal of Gynecological Pathology, 27, 353-365. https://doi.org/10.1097/PGP.0b013e31815c24fe

[64] KiKim, J.H., KiKim, T.J., Park, Y.G., Lee, S.H., Lee, C.W., Song, M.J., et al. (2009) Clinical Analysis of Intraoperative Frozen Section Proven Borderline Tumors of the Ovary. Journal of Gynecologic Oncology, 20, 176-180.

https://doi.org/10.3802/jgo.2009.20.3.176

[65] Brun, J.L., Cortez, A., Rouzier, R., Callard, P., Bazot, M., Uzan, S., et al. (2008) Factors Influencing the Use and Accuracy of Frozen Section Diagnosis of Epithelial Ovarian Tumors. American Journal of Obstetrics \& Gynecology, 199, 244. https://doi.org/10.1016/j.ajog.2008.04.002

[66] Bige, O., Demir, A., Saygili, U., Gode, F., Uslu, T. and Koyuncuoglu, M. (2011) Frozen Section Diagnoses of 578 Ovarian Tumors Made by Pathologists with and without Expertise on Gynecologic Pathology. Gynecologic Oncology, 123, 43-46. 
https://doi.org/10.1016/j.ygyno.2011.06.030

[67] Bonnamy, L., Fignon, A., Fetissof, F., Berger, C., Body, G. and Lansac, J. (2001) Tumeurs borderline de l'ovaire. Étude multicentrique à propos de 137 patientes. Journal de Gynécologie Obstétrique et Biologie de la Reproduction, 30, 272-281.

[68] Parker, W.H., Jacoby, V., Shoupe, D. and Rocca, W. (2009) Effect of Bilateral Oophorectomy on Women's Long-Term Health. Women Health, 5, 565-576. https://doi.org/10.2217/WHE.09.42

[69] Rinaudo, P. and Strauss 3rd, J.F. (2004) Endocrine Function of the Postmenopausal Ovary. Endocrinology \& Metabolism Clinics of North America, 33, 661-674. https://doi.org/10.1016/j.ecl.2004.07.005

[70] Bourdel, N. and Canis, M. (2013) Stratégies thérapeutiques des tumeurs ovariennes présumées bénignes. Journal de Gynécologie Obstétrique et Biologie de la Reproduction, 42, 802-815. https://doi.org/10.1016/j.jgyn.2013.09.035

[71] Morris, R.T., Gershenson, D.M., Silva, E.G., Follen, M., Morris, M. and Wharton, J.T. (2000) Outcome and Reproductive Function after Conservative Surgery for Borderline Ovarian Tumors. Obstetrics \& Gynecology, 95, 541-547.

https://doi.org/10.1097/00006250-200004000-00012 